\title{
Experimental Approach of Reflectance Based Vicarious Calibration Method for Solar Reflectance Wavelength Region of Sensor Onboard Remote Sensing Satellites
}

\author{
Kohei Arai ${ }^{1}$ \\ Graduate School of Science and Engineering \\ Saga University \\ Saga City, Japan
}

\begin{abstract}
Experimental approach of reflectance based vicarious calibration of solar reflectance wavelength region of mission instruments onboard remote sensing satellites is conducted. As an example, vicarious calibration of ASTER/VNIR with estimated aerosol refractive index and size distribution that depends on atmospheric conditions is discussed. Strange solution of estimated refractive index and size distribution may occurred due to the fact that solution fell into one of local minima in the inversion process for phase function fitting between measured and estimated with assumed refractive index and size distribution. This paper describes atmospheric conditions that may induce such a situation. Namely, it may occur when the atmospheric optical depth is too thin and or Junge parameter is too small. In such case, refractive index and size distribution estimation accuracy is poor. A relation between refractive index and size distribution estimation accuracy and estimation accuracy of the Top of the Atmosphere (TOA) radiance (vicarious calibration accuracy) is also clarified in particular for ASTER/VNIR vicarious calibration. It is found that $10 \%$ of the refractive index and size distribution estimation error causes approximately $1.3 \%$ of TOA radiance estimation error.
\end{abstract}

Keywords-Vicarious calibration; Top of Atmosphere Radiance, At sensor Radiance; refractive index; size distribution; Junge parameter; optical depth

\section{INTRODUCTION}

Visible and Near Infrared mounted on earth observation satellites and the short-wavelength infrared radiation thermometer, Alternative calibration using measurement data on the ground and onboard calibration by the calibration mounting system is performed. For example, Marine Observation Satellite-1 [1], Landsat-7 Enhanced Thematic Mapper Plus [2], SeaWiFS [3], High Resolution Visible: HRV/SPOT-1 and 2 [4], Hyperion [5], POLDER [6], etc. by ASTER [7]. The calibration results and the like have been reported. Further, report according to reciprocity with a uniform ground surface [8] over a wide area such as desert radiometer each other overlapping of the observation wavelength range have been made [9].

Vicarious calibration can be divided into approaches that are based on the radiance method based on reflectivity. The former to compute the calibration coefficients by the basis of the measurement data of the thickness atmospheric optical instruments from the ground surface reflectance and was placed on the ground, to estimate the atmospheric upper radiance, and compared with satellite radiometer data the contrast, estimates the upper atmospheric radiance also using the vertical measurement data of the thickness atmospheric optical equipped aircraft or the like, the latter is compared with satellite radiometer data. Since the latter requires a lot of costs, there is also a problem of the calibration accuracy of the radiometer mounted on an aircraft, the former is generally used.

Therefore, vicarious calibration is referred to as an alternate calibration simply alternative calibration based on reflectance unless otherwise specified hereinafter. Vicarious calibration method (Bi-Directional Reflectance Distribution Function if it is not the nadir: BRDF [10]) land surface reflectance measurement of optical thickness water vapor that contributes to dissipate in this wavelength range and measurement of aerosol, ozone, dry air "Alternative calibration based on reflectivity" profile calibrated by done, estimates the top of atmosphere radiance by solving the radiative transfer equation based on these satellite visible and near infrared and is compared with the short wavelength infrared radiometer data mostly is. Further, alternative calibration and calibration source which months do not have to consider the influence of the atmosphere is also conducted [11].

Furthermore, same or calibration, etc. through mutual comparison of sensor data of the same kind that are overlapping observation wavelength mounted on the other satellites are also performed [12]. [13], [14]. To conduct the error analysis in the vicarious calibration of visible and near infrared radiometer, Arai et al. made it clear dominant error factors of vicarious calibration accuracy [15]. According to it, error factors most dominant is the ground surface reflectivity, then found to be in the order of aerosol complex refractive index profile deduced from this, the estimation error of the particle size distribution and measurement errors in thickness atmospheric optical are. $\$ In addition, Root Sum Square of these factors: It is concluded that vicarious calibration 
accuracy of the $\operatorname{RSS}^{1}$ and is about $4 \%$. In addition, the complex refractive index and detailing the effect that estimation accuracy of the particle size distribution on the alternative calibration accuracy. Estimated thickness precision air optical, aerosol complex refractive index, the particle size distribution is dependent on the measurement accuracy sun direct light, rim light, of scattering light, I described in detail the calibration accuracy of the sky radiometer to measure these [16], [17].

Saga University in April 2003, Arai et al. have been doing the observation of aerosol by Sky radiometer. POM-1 sky radiometer you are using is (PREDE Co.) [18]. A device for measuring the scattered light and direct sunlight, to obtain the particle size distribution and the complex refractive index of the aerosol, it is necessary to estimate the scattered light and direct light sky radiometer. It is necessary to solve the inverse problem in this estimation. Is allowed to fit with the aerosol scattering phase function was calculated based on the volume particle size distribution and the complex refractive index observed scattered light is assumed [19], Nakajima propose a method of estimating the volume particle size distribution and the complex refractive index [20]. In addition, Arai we have proposed a method for using the Simulated Annealing: SA as inverse problem solution [21]. Furthermore, improved Langley method as the calibration method of sky radiometer and a method for estimating the top of atmosphere radiance using a method not only downward already proposed, solves the radiative transfer equation by dividing $\mathrm{p}$, the $\mathrm{s}$-polarized light component upward radiance I suggested a corrected and improved Langley method to introduce the concept of late Langley method [22].

Winning, reveal the particle size distribution and the complex refractive index in the case of focusing on the convergence of the particle size distribution and aerosol complex refractive index, which is a problem when the thin optical thickness, particularly fall into local minima, the alternative in this paper I to clarify the effects of calibration accuracy [23]. In addition, the complex refractive index and empirical complex refractive index and (volume particle size distribution) particle size distribution based solar direct, peripheral light, the scattered light measurement and the number of power law distribution, which is calculated from the spectral characteristics of the thick atmosphere optical have performed a comparison of the top of atmosphere radiance when used. The latter requires only instrument small and light whereas the former require heavy instrument relatively large. Therefore, it becomes able to determine the error in case of performing a top of atmosphere radiance estimation by the latter in the test site measurements such as the former is not feasible. In addition, at this time, to clear solar zenith angle of the top of atmosphere radiance, also the observation zenith angle characteristics, I have generalized the discussion.

\footnotetext{
${ }^{1} \mathrm{RSS}=\mathrm{SQRT}(\mathrm{dR} 2 \mathrm{dO} 2 \mathrm{dA} 2 \mathrm{dS} 2 \ldots)$, is a value expressed in percentage impact on the top of atmosphere radiance reflectance measurement error, the error measured optical thickness, complex refractive index estimation error of the particle size distribution estimation error $\mathrm{dR} 2, \mathrm{dO} 2, \mathrm{dA} 2, \mathrm{dS} 2$ wherein .
}

We introduce a method for estimating the particle size distribution and the complex refractive index in the second chapter, the relationship between the estimation accuracy of the particle size distribution and the complex refractive index and the calibration accuracy of the sky radiometer, particle size distribution and the complex refractive index in the third chapter. I describe the relationship between the vicarious calibration accuracy and the estimation accuracy of the particle size distribution the convergence of the estimation method, the complex refractive index.

\section{Method For Estimatingthe Particle Size DISTRIBUTION AND THE COMPLEX REFRACTIVE INDEX}

I described in this section from the particle size distribution and the complex refractive index of aerosols, the radiative transfer equation [24] to calculate the intensity of the ambient light and direct sun light. Expression of $\tau_{\mathrm{t}}$ optical thickness from (1), the optical thickness of the atmosphere can be calculated from the top of atmosphere incident illumination of $\mathrm{F}_{0}$ and solar observation illumination $\mathrm{F}$ of direct sun light.

$\mathrm{F}=\mathrm{F}_{0} \exp \left(-\mathrm{m}_{0} \tau_{\mathrm{t}}\right)$

where the air mass $\left(\theta_{0}\right), \theta_{0}$ shows the solar zenith angle $m_{0}=1$ / cos. Furthermore, the optical thickness of the atmosphere is represented by the formula (2).

$\tau_{\mathrm{t}}=\tau_{\mathrm{a}}+\tau_{\mathrm{m}}=\tau_{\mathrm{as}}+\tau_{\mathrm{aa}}+\tau_{\mathrm{ms}}+\tau_{\mathrm{ma}}$

where, $\tau$ represents the optical thickness. S index of molecule, the second character scattering, $\mathrm{a}$ is the absorption, the entire atmosphere, a is shown a dissipation factor of each aerosol, and $\mathrm{m} \mathrm{t}$ is the index of the first character. Effects of water molecules and ozone are large optical thickness by molecular absorption.

It is set so as to avoid the intense wavelength of molecular absorption they observed wavelength of the sky radiometer, the observation wavelength of $675 \mathrm{~nm}$ and $500 \mathrm{~nm}$ band ozone absorption, $1020 \mathrm{~nm}$ receive slightly the effect of water molecules absorbed. Next, observation of the solar irradiance scattered light is represented by the formula (3).

$\mathrm{E}\left(\theta_{0}, \varphi\right) \equiv \mathrm{E}(\Theta)=\mathrm{F}_{\mathrm{m} 0} \Delta \Omega\left[\omega \tau_{\mathrm{t}} \mathrm{P}(\Theta) \mathrm{q}(\Theta)\right]$

where, (the difference between the solar azimuth angle and observation azimuth) relative azimuth, $\Theta$ shows a sounding scattering angle with respect to the zenith angle of the sun $\varphi$. Relational expression (4) holds between the respective angles.

$\cos (\Theta)=\cos ^{2} \theta_{0} \sin ^{2} \theta_{0} \cos \varphi$

In addition, observation of solar illumination direct light, it is $\Delta \Omega\left(\tau_{\text {as }} \tau_{\mathrm{ms}}\right) / \tau_{\mathrm{t}}$ single scattering albedo, $\mathrm{P}$ is $(\Theta)$ scattering phase function of the atmosphere, F observation solid angle of the sky radiometer, $\omega=\mathrm{q}(\Theta)$ I show the contribution of multiple scattering. Then, I think the $(\Theta)$ element R to stable independent of the calibration coefficient of the sky radiometer. 
$\mathrm{R}(\Theta)=\mathrm{E}(\Theta) / \mathrm{F}_{\mathrm{m} 0} \Delta \Omega=\omega \tau_{\mathrm{t}} \mathrm{P}(\Theta) \mathrm{q}(\Theta) \equiv \beta(\Theta) \mathrm{q}(\Theta)$

Divided by the solid angle $\Delta \Omega$ observation illumination $\mathrm{F}$ of direct light, air mass $\mathrm{m} 0$, Sky radiometer observations illumination $\mathrm{E}$ of solar scattered light $(\Theta)$, R represented by the formula $(4)(\Theta)$ is or change each it is obtained by suppressing the error with respect to calibration. Therefore, it is a physical quantity which depends on only the state of the atmosphere.

Further, replacing the $(\Theta), \beta(\Theta)$ denotes the intensity of single scattering $(\Theta)=\beta \omega \tau_{\mathrm{t}} \mathrm{P}$. By equation (5), it can be decomposed into the scattering phase function of aerosol scattering $\mathrm{P}_{\mathrm{a}}(\Theta)$ molecular scattering and $\mathrm{P}_{\mathrm{m}}(\Theta)$ scattering phase function is $P(\Theta)$.

$\mathrm{P}(\Theta)=\left\{\tau_{\mathrm{ms}} \mathrm{P}_{\mathrm{m}}(\Theta) \tau_{\mathrm{as}} \mathrm{P}_{\mathrm{a}}(\Theta)\right\} /\left(\tau_{\mathrm{ms}} \tau_{\mathrm{as}}\right)$

Compared to the observed wavelength $\lambda$ of the sky radiometer $r_{m}$ particle size of the molecule is very small $\left(\pi r_{m} /\right.$ $\lambda<0.4)$. Therefore, the molecular scattering can be represented by Rayleigh scattering, the optical thickness $\tau_{\mathrm{ms}}$ scattering phase function Pm Rayleigh scattering $(\Theta)$, obtained by (8) and (7), respectively equation .

$\mathrm{P}_{\mathrm{m}}(\Theta)=(3 / 4)\left(1 / \cos ^{2} \Theta\right)$

$\tau_{\mathrm{ms}}=\{0.008569 \lambda-4(1+0.0113 \lambda-20.00013 \lambda-4)\}\left(\mathrm{p} / \mathrm{p}_{0}\right)\left(\mathrm{T}_{0} / \mathrm{T}\right)$

Ground temperature, T, $\mathrm{P}$ is the pressure, $(288.15 \mathrm{~K}$, $1013.25 \mathrm{hPa}$ ) T0, p0 is a standard temperature, pressure here. The particle size of the aerosol $r_{a}, 0.4<\pi r_{a}$ the observed wavelength $\lambda$ of the sky radiometer $/ \lambda$ is in a relationship $<3$. Therefore, I can be considered by the Mie theory scattering by aerosol.

Aerosol scattering intensity $\beta_{\mathrm{a}}$ and $\tau_{\text {as }}$ optical thickness due to Mie scattering $(\Theta)$, is determined by $(9)$ each formula.

$$
\begin{array}{r}
\beta_{a}(\Theta)=\frac{\lambda^{2}}{2 \pi} \int_{r_{\min }}^{r_{\max }}\left[i_{1}(\Theta, x, \tilde{m})+i_{2}(\Theta, x, \tilde{m})\right] n(r) d r \\
\tau_{a}=\int_{r_{\min }}^{r_{\max }} \pi r^{2} Q_{e x t}(x, \tilde{m}) n(r) d r
\end{array}
$$

where, $r$ the radius of the particle, the maximum radius $r_{\max }$ and $r_{\min }$ complex refractive index minimum radius and $\mathrm{a} \sim \mathrm{m}$, size parameter, $\mathrm{n}(\mathrm{r})=\mathrm{dN} \mathrm{x}=(2 \pi / \lambda) \mathrm{r}$ to $(\mathrm{r}) / \mathrm{dr}$ is number particle size distribution included in the unit of the air column aerosol particles $\left[1 / \mathrm{cm}^{2} / \mu \mathrm{m}\right]$, scattering efficiency, which is determined by Mie theory, $\mathrm{Q}_{\mathrm{ext}}(\mathrm{x}, \sim \mathrm{m})$ and $\mathrm{i}_{1} \mathrm{i}_{2}$ Me intensity function in (Mie Intensity Function) some . Is used number particle size distribution $\mathrm{n}$ and ( $\mathrm{r}$ ) as the particle size distribution of aerosols, using a volume particle size distribution $\mathrm{v}(\mathrm{r})=\mathrm{dV} / \mathrm{d} \ln \mathrm{r}$ a $[\mathrm{cm} 3 / \mathrm{cm} 2]$ as a particle size distribution of the aerosol here. There is a relationship of formula (10) (r) n v and (r). $v(r)=(4 / 3) \pi r 4 n(r)$

When defined in formula $(11)(\mathrm{x}, \sim \mathrm{m} \Theta$, ) the kernel function and $K_{\text {ext }} K(x)$, equation (9) is replaced by equation (12) .

$$
\begin{aligned}
& K_{\text {ext }}(x, \tilde{m})=\frac{3}{4} \frac{Q_{e x t}(x, \tilde{m})}{x}, K(\Theta, x, \tilde{m})=\frac{3}{2} \frac{i_{1}(\Theta, x, \tilde{m})+i_{2}(\Theta, x, \tilde{m})}{x^{3}} \\
& \beta_{a}(\Theta)=\frac{2 \pi}{\lambda} \int_{r_{\min }}^{r_{\max }} K(\Theta, x, \tilde{m}) v(r) d \ln r \\
& \tau_{a}=\frac{2 \pi}{\lambda} \int_{r_{\min }}^{r_{\max }} K_{\text {ext }}(x, \tilde{m}) v(r) d \ln r
\end{aligned}
$$

In addition, $P_{a}(\Theta)=\beta_{a}$ is a $(\Theta) / \omega_{a} \tau_{a}, \omega_{a}$ is the single scattering albedo of the aerosol.

Then, I think the contribution of multiple scattering. Is approximated by the equation (13) observed luminance $\mathrm{L}$ of the sun scattered light considering multiple scattering $(\Theta)$. Becomes equation (14) can be represented by observing illumination $\mathrm{E}(\Theta)$ this.

$$
\begin{aligned}
& L(\Theta) \simeq F_{0} m_{0} \exp \left(-m \tau_{t}\right)\left[\left(\tau_{m s}+\tau_{M S}\right) P_{m}(\Theta)+\tau_{a s} P_{a}(\Theta)+\tau_{A} P_{m}\left(0^{\circ}\right)\right] \\
& E(\Theta) \simeq F_{0} m_{0} \Delta \Omega \exp \left(-m \tau_{t}\right)\left[\left(\tau_{m s}+\tau_{M S}\right) P_{m}(\Theta)+\tau_{a s} P_{a}(\Theta)+\tau_{A} P_{m}\left(0^{\circ}\right)\right]
\end{aligned}
$$

The observation illumination, of light by multiple scattering in the atmosphere is $\tau_{\mathrm{MS}} \mathrm{P}_{\mathrm{m}}(\Theta)$, Rayleigh scattering minutes, further, $\tau_{\mathrm{aS}} \mathrm{P}_{\mathrm{m}}(\Theta)$ is the aerosol scattering minutes $\tau_{\mathrm{mS}} \mathrm{P}_{\mathrm{m}}$ is $(\Theta)$ here. Indicate the observation illumination of light multiple scattering more ground reflected light $\left(0^{\circ}\right) \tau_{\mathrm{A}} \mathrm{P}_{\mathrm{m}}$. Therefore,

$\mathrm{F}_{0} \mathrm{~m}_{0} \Delta \Omega \exp \left(-\mathrm{m} \tau_{\mathrm{t}}\right)\left(\tau_{\mathrm{ms}} \tau_{\mathrm{MS}}\right) \mathrm{P}_{\mathrm{m}}(\Theta)$ : illumination of the light scattered by molecules:,

$\mathrm{F}_{0} \mathrm{~m}_{0} \Delta \Omega \exp \left(-\mathrm{m} \tau_{\mathrm{t}}\right) \tau_{\mathrm{as}} \mathrm{P}_{\mathrm{a}}(\Theta)$ : illumination of the light scattered by aerosol:,

$\mathrm{F}_{0} \quad \mathrm{~m}_{0} \Delta \Omega \exp \left(-\mathrm{m} \tau_{\mathrm{t}}\right) \quad \tau_{\mathrm{A}} \mathrm{P}_{\mathrm{m}}\left(0^{\circ}\right)$ : the sum of the illumination of the light scattered in the air further to the ground surface reflection is the observation illumination. In addition, $\tau_{\mathrm{A}}$ and $\tau_{\mathrm{MS}}$ is a component corresponding to the optical thickness of each. In addition, $\tau_{\mathrm{A}}$ and $\tau_{\mathrm{MS}}$ represented by the formula (15), respectively formula empirically [25].

$$
\begin{array}{r}
\tau_{M S}=0.02 \tau_{S S}+1.2 \tau_{S S}^{2} \mu_{0}^{-\frac{1}{4}} \\
\tau_{A}=\frac{A \tau_{2}}{1-A \tau_{3}}
\end{array}
$$

where, the optical thickness of the single scattering, $\mu_{0}=\cos$ $\left(\theta_{0}\right), \tau_{\mathrm{SS}}=\tau_{\mathrm{ms}} \tau_{\mathrm{sa}}$ the surface albedo, $\tau_{2}=1.34 \tau_{\mathrm{SS}} \mu_{0}[1+0.22$ $\left.\left(\tau_{\mathrm{SS}} / \mu_{0}\right)^{2}\right], \tau_{3}=0.9 \tau_{\mathrm{SS}}-0.54 \tau_{\mathrm{SS}}{ }^{2}+0.92 \tau_{\mathrm{SS}}$.

When adapting the formula (15) in equation (2), Formula (16) wherein q contribution of multiple scattering $(\Theta)$.

$$
\mathrm{q}(\Theta) \fallingdotseq \tau_{\mathrm{MS}} \mathrm{P}_{\mathrm{m}}(\Theta)+\tau_{\mathrm{A}} \mathrm{P}_{\mathrm{m}}\left(0^{\circ}\right)
$$


So far, describing the method of calculating $\mathrm{R}$ illumination of solar light scattering and direct sun light the $F(\Theta)$ particle size distribution of $\mathrm{v}(\mathrm{r})$ and the complex refractive index $\sim \mathrm{m}$ of aerosol. Then, I calculate the complex refractive index $\sim \mathrm{m}$ of aerosol particle size distribution: v (r) $\mathrm{R}$ illumination of solar light scattering and direct sun light from $F(\Theta)$. For this purpose, it is necessary to solve a non-linear inverse problem. You are using an iterative method based on the equation (17) as the solution of inverse problem in. Skyrad.Pack ver.4.2.
$\beta_{\mathrm{a}}(1)(\Theta)=\mathrm{R}_{\text {mean }}$
$(\Theta) \beta_{\mathrm{a}}(\mathrm{n}+1)$
$(\Theta)=R_{\text {mean }}$
$(\Theta) R(n)(\Theta) \beta_{a}$
(n) $(\Theta)$

where, the number of iterations superscript of $\mathrm{R}$ and $\beta_{\mathrm{a}}$ is (n), $\mathrm{R}_{\text {mean }}$ shows the scattered light illumination was observed.

Equation (4), with respect to the scattered light illumination $\mathrm{R}_{\text {mean }}$ was observed, optimal single scattering illumination $\beta$ This technique is a method for calculating multiple scattering contribution and $q(\Theta)$ and $(\Theta)$. Further, to obtain $R(n)$ and $(\Theta)$, it is necessary to estimate the complex refractive index $\sim \mathrm{m}$ aerosol corresponding to $\beta(\mathrm{n})$ particle size distribution and $v(n)(n)$ and (r). It is necessary to solve the inverse problem further in order to calculate particle size distribution and $\mathrm{v}(\mathrm{n})(\mathrm{n})$ and $(\mathrm{r}) \sim \mathrm{m}$. The use of MoorePenrose generalized inverse matrix in this paper. First, g a matrix consisting of (n-1) $\left(\tau_{\mathrm{a}}(0)\right.$ is the observed value) of $\tau_{\mathrm{a}}$ optical thickness of the aerosol scattering illumination $\beta_{\mathrm{a}}$ aerosol $(\mathrm{n})$ and $(\Theta)$, particle size distribution $\mathrm{v}$ unknown (I place with the vector $\mathrm{v} n$ ) of ( $\mathrm{r}$ ). Given $\mathrm{g}$ of calculation than a $\mathrm{v}$ to contain error $\varepsilon, \mathrm{g}$ is expressed by equation (18).

$$
\mathrm{g}=\mathrm{Av}+\varepsilon
$$

where, $\mathrm{A}$ is a linear polynomial matrix for calculating the $\mathrm{g}$ from $\mathrm{v}$. At this time, $\mathrm{v}$ that minimizes $\varepsilon$ can be calculated by the formula (19) using the least-squares type generalized inverse matrix, $\left(\mathrm{A}^{\mathrm{T}} \mathrm{A}+\gamma \mathrm{H}\right)^{-1} \mathrm{~A}^{\mathrm{T}}[26]$.

$v=\left(A^{T} A+\gamma H\right)^{-1} A^{T} g$

where, $A^{T}$ is the transposed matrix of $A, \gamma$ indicates a smoothing matrix Lagrange multiplier, and $\mathrm{H}$, of course, downward based on Arai - Ryo model in upward radiance calculation, is calculated by dividing $\mathrm{p}$, the s-polarized light component.

It is possible to set the initial particle size distribution $\mathrm{v}(\mathrm{n})$ and $(r)$ In this manner, the provision of $R(n)$ and $(\Theta)$. In addition, I $\tau_{\mathrm{a}}(\mathrm{n})$ and the Aerosol Optical Thickness sought new at this time. By making repeated until convergence (18) in this way, complex (r) and particle size distribution $\mathrm{v}$ aerosol corresponding $\tau_{\text {mean }}$ optical thickness illumination $R_{\text {mean }}$ of scattered light was observed, and $(\Theta)$ to $\left(\lambda_{\mathrm{k}}\right)$ it is possible to calculate the refractive index $\sim \mathrm{m}$. It is considered to have converged when it meets one of the conditions of the conditional expression (20).

$$
\begin{array}{r}
\varepsilon^{(1)}<0.01 \\
\left|\varepsilon^{(n)}-\varepsilon^{(n-1)}\right|<0.001 \\
n \geq 5
\end{array}
$$

The $\varepsilon(n)$ RMSE is a Root Mean Square Error, is expressed by equation (21) here.

$$
\varepsilon^{(n)}=\sqrt{\frac{1}{2 J} \sum^{J}\left(\frac{R^{(n)}\left(\Theta_{j}\right)}{\left.R^{\text {mean }}\left(\Theta_{j}\right)\right)}-1\right)^{2}+\frac{1}{2 K} \sum^{K}\left(\frac{\tau^{(n)}\left(\lambda_{k}\right)}{\tau^{\text {mean }}\left(\lambda_{k}\right)}-1\right)^{2}}
$$

The index of the observation wavelength, $\mathrm{J}$ is the number of observation wavelength total number of scattering angle, $\mathrm{K}$ index of the scattering angle, $\mathrm{k}$ is the $\mathrm{j}$ here. Further, when the cutlet $\varepsilon(n)>0.5$, the complex refractive index and ends the estimation of the particle size distribution is determined $\beta(n)$ not to converge $(\Theta)$ with $n \geq 2$. Therefore, I will not converge optical thickness becomes very thin. Furthermore, as described below, do not guarantee a global optimum, it is falling into local minima may in this iterative method. That is, since less originally the difference between the estimated scattering phase function measurement and scattering phase function estimation error increases and is considered the solution has converged in the state they do not a best fit when the optical thickness is thin .

\section{EXPERIMENTS}

\section{A. Relationship complex refractive index and the calibration factor, and the particle size distribution}

Direct sun light, rim light and I is shown in Figure 1.

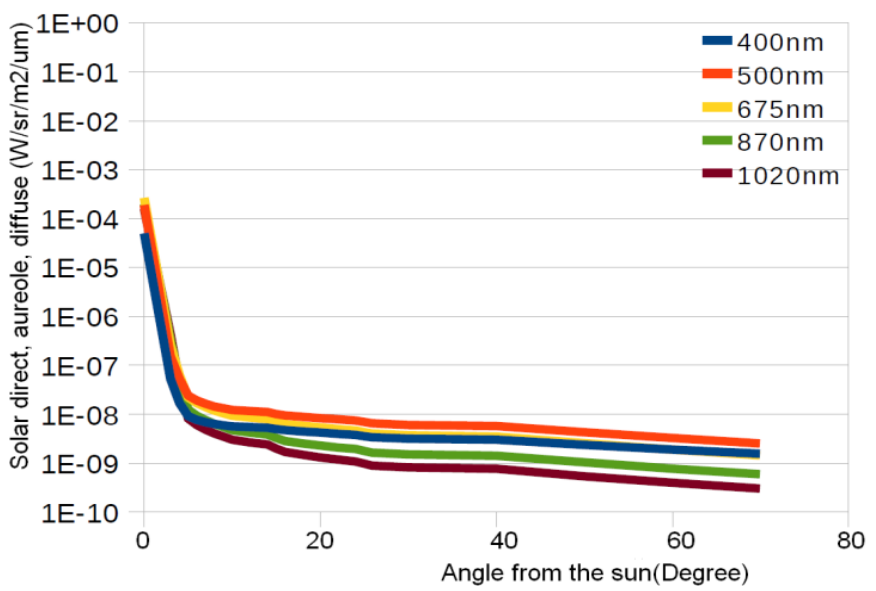

Fig. 1. Example of solar direct, aureole, diffuse irradiance measured on the ground (Angle from the sun $=0$ means direct solar light, 5 to 20 degree of range of angle from the sun means aureole and the other angle means diffuse light)

An example of the scattered light was calibrated by using the data of sky radiometer that is observed by Saga University. Arai - Ryo model [27] correction improved Langley method based on algorithm was used for calibration. The calibration coefficient of daily observation, error observation error of sky radiometer and the estimation error of the atmospheric 
conditions, by regression error of the Langley plot at the time included. Therefore, it is necessary to think statistically calibrate the radiometer sky. Figure 2 shows the change in the calibration factor of the sky radiometer. I seen twice is a large change in the calibration factor for each wavelength. 1 time is June 2004; the second time is July 2008. Is referred to as the " third term " changes since " two stage" , the second time period between the second "stage $1 "$, and the first time the first time earlier in this paper. July 2008 a second time (period $2 \rightarrow 3$ phase) is the time you have made the (test) maintenance of sky radiometer, the calibration factor is increased compared with that before.

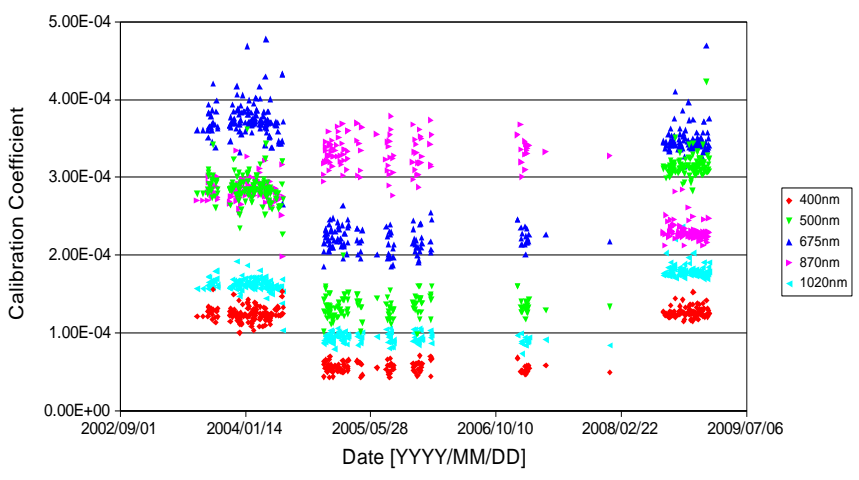

Fig. 2. Trend of calibration coefficient of the skyradiometer of POM-01 manufactured by Prede Co. Ltd. equipped at Saga University

Verify Error Analysis by the variation of the estimation result when an error is included in the calibration factor. The estimated particle size distribution and aerosol complex refractive index using the observation data, October 15, 2008. Using the average value of the three phase, it calibration factor was estimated in addition to deliberately error to $10 \%-10 \%$.

First, recalculate the optical thickness by filling in the radiative transfer equation the volume particle size distribution and the complex refractive index was estimated using a sky radiometer data and the optical thickness was observed by sky radiometer. I was comparing the optical thickness that was observed this optical thickness was recalculated. At this time, if you are able to correctly estimate the particle size distribution and the complex refractive index, optical thickness that was observed with the optical thickness that is recalculated are equal. Therefore, it was thought that if the trust radiative transfer equation ${ }^{2}$ [29], the estimation accuracy of the particle size distribution and the complex refractive index could be evaluated.

Figure 3 shows the results. Aerosol complex refractive index and solved the inverse problem so as to fit the observed values scattered light intensity and the optical thickness when estimating the particle size distribution, the optical thickness 's can fit more Figure 3 is, I can be seen that the error is only a few $\%$ range about \pm . Specifically, other ranges can be seen that the solution of the inverse problem cannot be obtained satisfactorily. The reason for this is because the conflict began

\footnotetext{
2 As can be seen from reference [29] of Lenoble, according to the mutual comparison of the top of atmosphere radiance calculated by the radiative transfer equation previously proposed most of the ground surface conditions and the same atmosphere, those differences are $1 \%$ to be less than is known.
}

to arise in the relationship of the scattered light intensity and optical thickness from that error of the calibration factor is large.

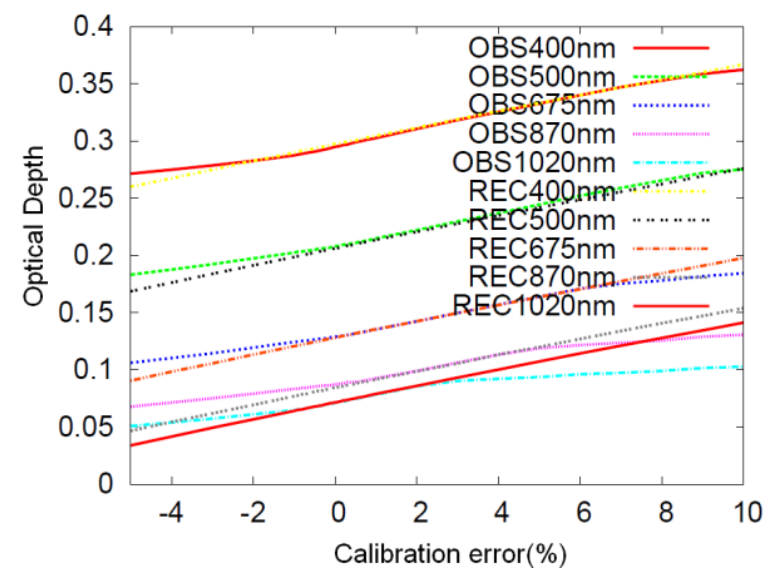

Fig. 3. Measured and re-estimated optical depth as a function of calibration error of the skyradiometer used of which the measurements is conducted at Saga University on October 152008.

Here, since the particle size distribution in terms of the number (number distribution) can be approximated by a power distribution is called the number of power distribution. This paper was assumed (Truncated Power Law) censoring power law distribution based on the Junge parameters shown in the following as (r) number of power law distribution $n$.

$\begin{array}{ll}\mathrm{n}(\mathrm{r})=\mathrm{C} 10^{v+1} & (\mathrm{r} \leq 0.1 \mu \mathrm{m}) \\ \mathrm{n}(\mathrm{r})=\mathrm{Cr}^{-(\mathrm{v}+1)} & (\mathrm{r}>0.1 \mu \mathrm{m})\end{array}$

where, $r$ indicates the diameter. The upper limit of $r$ depends on the above equation. I expressed by the aerosol concentration coefficient $\mathrm{C}$ and Junge parameter $v$ is censoring power law distribution. $\mathrm{C}$ represents the overall height of the piece power distribution precisely. The concentration of aerosol varies with Junge parameter $v$ even though constant $C$ that does not mean that $\mathrm{C}$ represents the concentration itself. However, it is referred to as the $\mathrm{C}$ concentration for convenience in this paper. To derive the optical thickness from the complex refractive index and particle size distribution, I calculate the Mie theory. I was used mie2new.f is attached software of MODTRAN is Mie theory calculations.

As shown in (experimental data in Saga University on October 15, 2008) Figure 4, in general, bimodal characteristic is a (bimodal) but volume particle size distribution is unimodal characteristics by the number power law distribution to be represented by the Junge parameter is a (uni-modal). Further, because of the use of a Junge parameter indexed to the best approximation coefficients are not suitable only average and particle size distribution of reality. Therefore, the volume particle size distribution by the log-normal distribution expression is appropriate if you are a strict discussion. However, Junge parameter is characterized by to be approximated from (can be obtained from the spectral characteristics of the optical thickness of the atmosphere) angstroms exponential mathematical is easy to handle a single 
parameter. As will be described later, the difference of the estimated top of atmosphere radiance assuming the number of power distribution single parameter by (Junge parameter) and assuming a volume particle size distribution by a lognormal expression 1 in typical atmospheric conditions, it is about $2 \%$. Therefore, it is necessary to allow the error when employing the number of power distribution. In other words, if it is brought into the crowded test site instruments large and heavy, such as Sky radiometer is difficult there are many alternative calibration, there is no choice but to allow the error of $1,2 \%$.

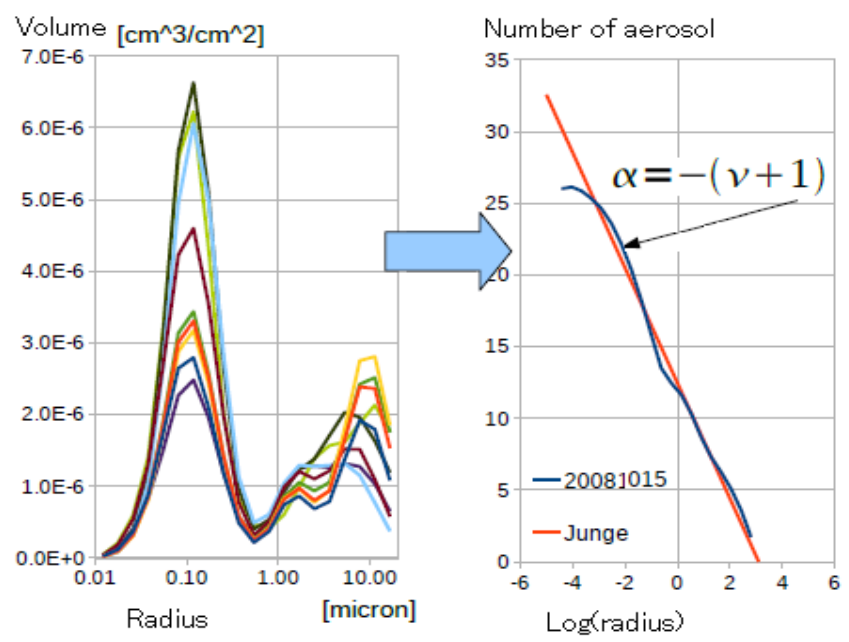

(a) Volume spectrum, Size distribution (b) Number of aerosol particle distribution (vdenotes Junge parameter)

Fig. 4. An example of relation between volume spectra and Junge distribution that are observed at Saga University on October 152008.

Complex refractive index that is estimated based on the sky radiometer data acquired in Saga on October 15, 2008 and is shown in Figure 5 the variation of Junge parameter. Complex refractive index real part is found to be nearly invariant to changes in the calibration factor. In addition, Junge parameter is also increased calibration coefficient becomes larger. In addition, the complex refractive index imaginary part has significant change with respect to changes in the calibration factor; the imaginary part is smaller remarkably calibration factor becomes larger. Complex refractive index imaginary part become smaller calibration factor becomes larger, it is because the optical thickness of the atmosphere becomes thick calibration factor is increased; the absorption of the aerosol would have been estimated large.

From the above, errors of $2-3 \%$ is included in the calibration factor, I found that the estimated value of the complex refractive index imaginary part is affected most greatly. In addition, I found that Junge parameter varies about $3 \%$, the complex refractive index real part hardly changes. This, I am suggesting from the fact that the error of the calibration factor is increased, the optical thickness estimated the optical thickness that was observed cannot be fit.

Complex refractive index and using the mean of the estimates of $12: 00$ to 11:00 when evaluating estimation accuracy of the particle size distribution. This time zone is the time zone is the shortest air mass; it is also a time zone Terra satellite passes over the saga further. The observed number of days estimated successful in the time range of 12:00 to 11:00, Phase 1 period 95 days, Phase 2139 days, Phase 3 period is 68 days.
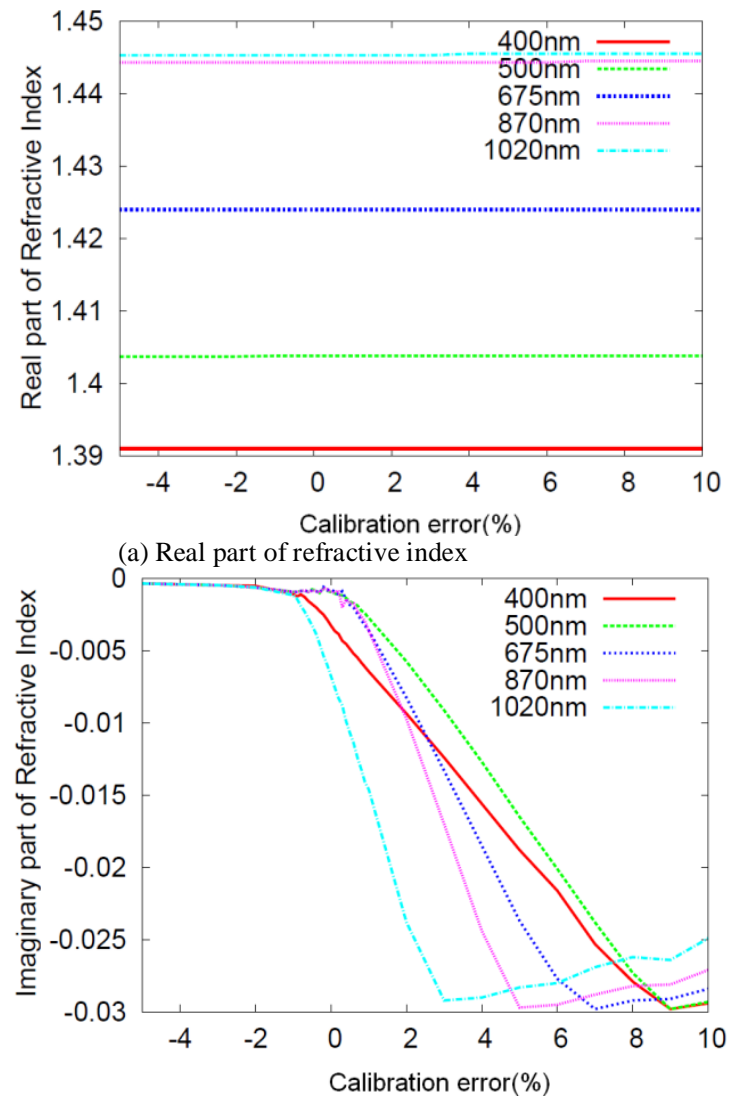

(b) Imaginary part of refractive index

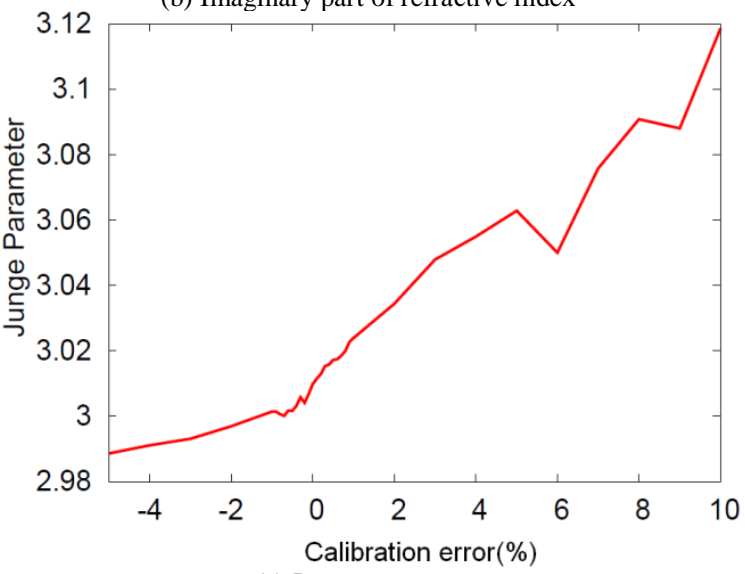

(c) Junge parameter

Fig. 5. Relations between calibration error and refractive index and Junge parameter measured at Saga University on October 152008.

Physical amount estimated is three volume particle size distribution of the total aerosol in the air columns complex refractive index real part of the aerosol, the complex refractive index imaginary part, of the unit area $\left[\mathrm{cm}^{3} / \mathrm{cm}^{2}\right]$. I is shown in Figure 6 (a) an estimate of the Junge parameter and asymmetry parameters complex refractive index real part, imaginary part, the phase function. Complex refractive index that was estimated, based on the particle size distribution, to obtain the phase function using (mie2new.f) Mie scattering 
code that is provided software MODTRAN, was determined Junge parameters and asymmetry parameter. In the figure, upper complex refractive index real part, middle asymmetry parameter, diamond symbol is shown (negation, x100) the complex refractive index imaginary part data of cold color and Junge parameter. In order to investigate the trends in the estimates for calibration factors will be considered as limited to only the data that satisfies the following conditions.

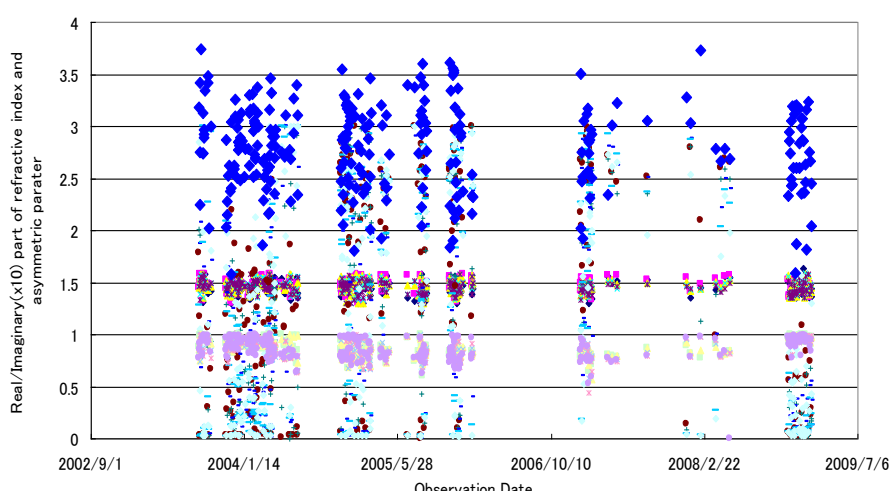

(a) Trends of the estimated real part (around 1.5) and minus imaginary part $\mathrm{x} 100$ (ranges from 0 to 3 ) of refractive index as well as asymmetric parameter (around 1) together with Junge parameter ( $)$ (271 of data in total are plotted).

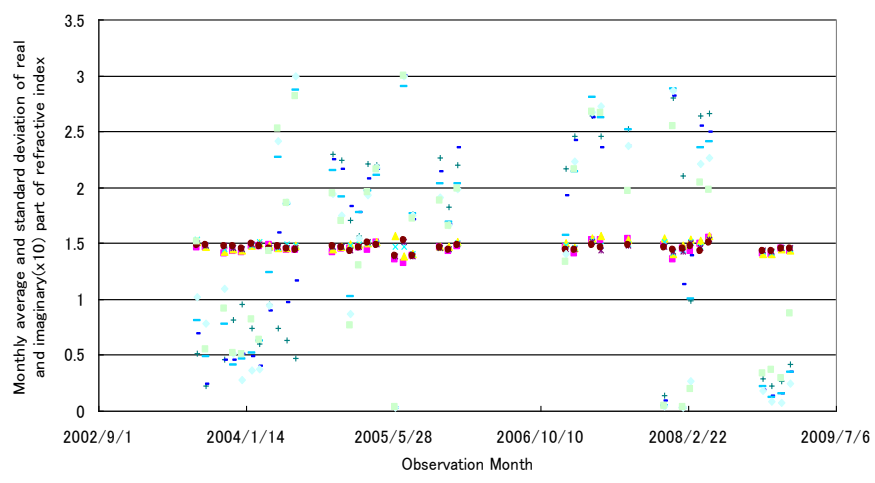

(b) Monthly average of real and minus imaginary (x 100) part of refractive index

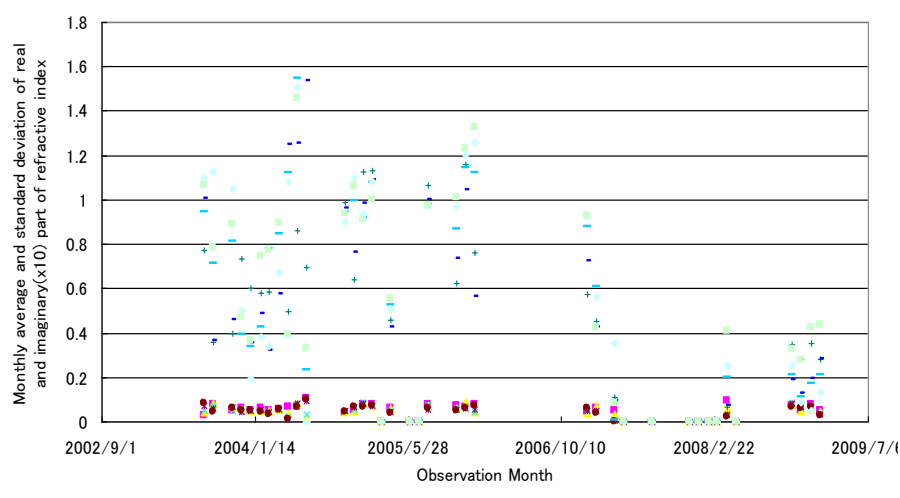

(c) Monthly standard deviation of real and minus imaginary (x 100) part of refractive index.

Fig. 6. Trends of the estimated refractive index and asymmetric parameter with measured skyradiometer data at Saga University during August 2003 and February 2009 (The number of samples a month ranges from 0 to 20). (Warm colored dots show standard deviation of real part (around 0.08) while cold colored dots show imaginary part of refractive index).
Conditions: Sunny, from 11:00 12:00 (average), 1 or less cloud cover 9:00, visibility $10 \mathrm{~km}$, Dongfeng ${ }^{3}$

Weather conditions of these were with reference to the observations by the Japan Meteorological Agency. For the day of fine weather there is no effect of clouds on the observation of the sky radiometer, (the same applies to cloud cover) that can be expected estimate of aerosol stable. It is a period of time where you can expect the estimated stable since the time zone is the shortest air mass is 12:00 to 11:00. Visibility indicates the amount of aerosols and air molecules indirectly. Aerosol come is carried on the wind. It is considered to be shown (complex refractive index, Junge parameters) like features aerosol coming carried aboard the easterly, because the same wind, same time zone, aerosol in the same season. Complex refractive index real part of the estimated is shown in Figure 6 (b), in Table 1, and (c) and the standard deviation and the monthly average of the imaginary part. Warm data is complex refractive index real part, cold color data shows the imaginary part in the figure. Complex refractive index imaginary part also shows seasonal variation with a tendency corresponding to the calibration accuracy. I also showed confidence intervals at $95 \%$ confidence level as a result of the t-test of the average value of the complex refractive index estimated in Table 1.

TABLE I. MONTHLY AVERAGE, STANDARD DEVIATION AND CONFIDENCE INTERVAL AT 95\% OF CONFIDENCE LEVEL OF ESTIMATED

REAL AND IMAGINARY PART OF REFRACTIVE INDEX WITH MEASURED

SKYRADIOMETER DATA DURING AUGUST 2003 AND FEBRUARY 2009.

\begin{tabular}{|l|l|l|l|l|r|}
\hline Real part & $400 \mathrm{~nm}$ & $500 \mathrm{~nm}$ & $675 \mathrm{~nm}$ & $870 \mathrm{~nm}$ & $1020 \mathrm{~nm}$ \\
\hline Average & 1.4458 & 1.4806 & 1.4737 & 1.4663 & 1.4579 \\
\hline Standard Deviation & 0.04919 & 0.04814 & 0.03018 & 0.03131 & 0.02748 \\
\hline $\begin{array}{l}\text { Confidence } \\
\text { Interval@95\% }\end{array}$ & $\begin{array}{l}0.00035 \\
57\end{array}$ & $\begin{array}{l}0.00034 \\
82\end{array}$ & $\begin{array}{l}0.00021 \\
83\end{array}$ & $\begin{array}{l}0.00022 \\
64\end{array}$ & $\begin{array}{l}0.00019 \\
88\end{array}$ \\
\hline Imaginary part & $400 \mathrm{~nm}$ & $500 \mathrm{~nm}$ & $675 \mathrm{~nm}$ & $870 \mathrm{~nm}$ & $1020 \mathrm{~nm}$ \\
\hline & - & - & - & - & - \\
Average & 0.01453 & 0.01417 & 0.01442 & 0.01392 & 0.01411 \\
\hline Standard Deviation & 0.09518 & 0.09337 & 0.09579 & 0.09799 & 0.08828 \\
\hline $\begin{array}{l}\text { Confidence } \\
\text { Interval@95\% }\end{array}$ & $\begin{array}{r}0.00068 \\
84\end{array}$ & $\begin{array}{r}0.00067 \\
53\end{array}$ & $\begin{array}{r}0.00069 \\
28\end{array}$ & $\begin{array}{r}0.00070 \\
87\end{array}$ & 0.00063 \\
\hline
\end{tabular}

Confidence interval as compared to the average, two orders of magnitude smaller is also the wavelength difference between the estimation of the complex refractive index of the measurement day different is significant with $5 \%$ level. Therefore, it is considered that the complex refractive index of the measurement date was selected as described above, and is similar to the nature of the aerosol parameters, etc. Junge. Further, the average trend of the complex refractive index imaginary part of Figure 6 (b) is the complex refractive index and the imaginary (calibration coefficients tendency similar trend calibration factor Sky radiometer in Figure 2 As is clear from this table there is shown portion is high in the first phase, and low in the second phase, and a) shows high values in the third phase, estimation of the complex index of refraction can be seen that it has much to do with the calibration factor. That is, as described above, I assumed that fall into a local solution

${ }^{3}$ http://www.jma.go.jp/jma/index.html 
in iterative methods for calibration accuracy is insufficient; the estimation accuracy of the complex refractive index imaginary part is reduced.

\section{B. The effect on the top of atmosphere radiance}

I examined the change in the top of atmosphere radiance to changes in particle size distribution and the complex refractive index of the aerosol. Vicarious calibration target is ASTER / VNIR of Terra satellite. Pick up the field campaign was carried U.S.A. in Nevada Railroad Valley Playa on September 21, 2008 and July 30, 2006 as an example, the complex refractive index and the effect of particle size distribution shows an effect on the top of atmosphere radiance. The test site, Railroad Valley Playa, there is a permanent direct sun light, rim light and the equipment to measure the scattered light as well as the sky radiometer Aureolemeter as part of AERONET [28]. Figure 7, 8 shows the particle size distribution and the complex refractive index estimated from the sky radiometer data and optical thickness, respectively.

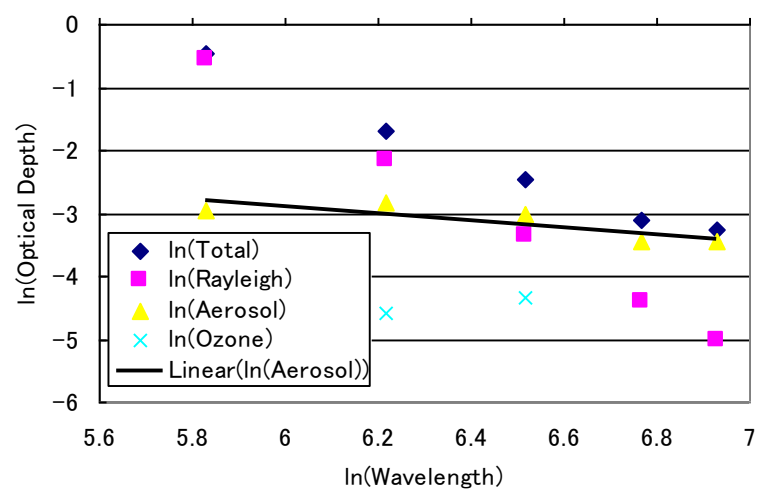

(a) Angstrome exponent and optical depth (21 September 2008)

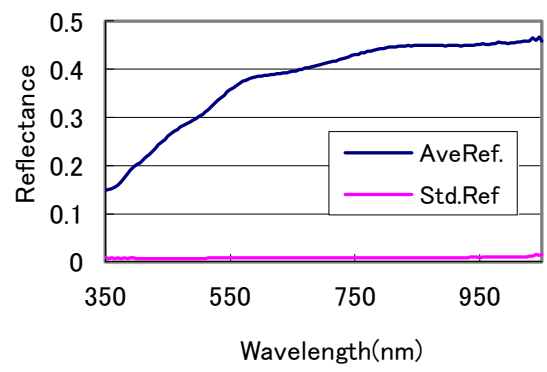

(b)Average and standard deviation of surface reflectance (21 September 2008)

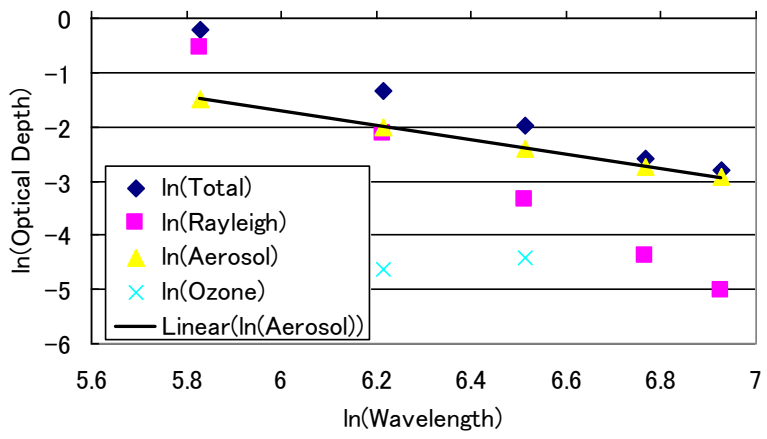

(c) Angstrom exponent and optical depth (30 July 2006)

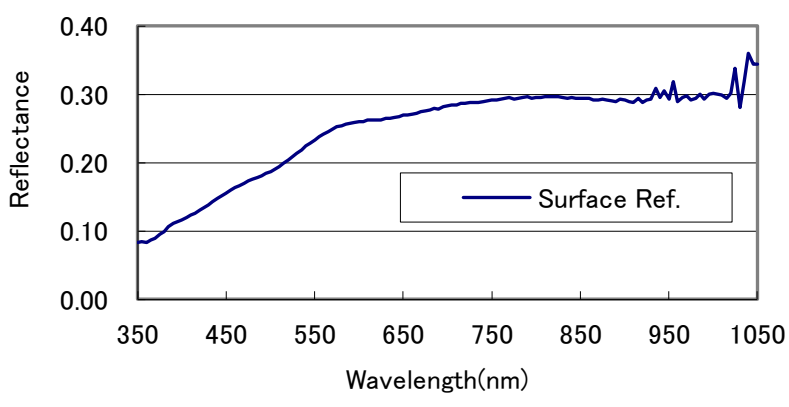

(d)Averaged surface reflectance (30 July 2006)

Fig. 7. Measured optical depth (as well as Angstrom exponent) at Railroad valley playa on (a) 21 September 2008 and at Railroad valley playa on (b) 30 July 2006 ( $\ln$ (wavelength) of 5.8, 6.2, 6.5, 6.75 and 6.87 is corresponding to the wavelength of $340,500,675,870$ and $1020 \mathrm{~nm}$, respectively).

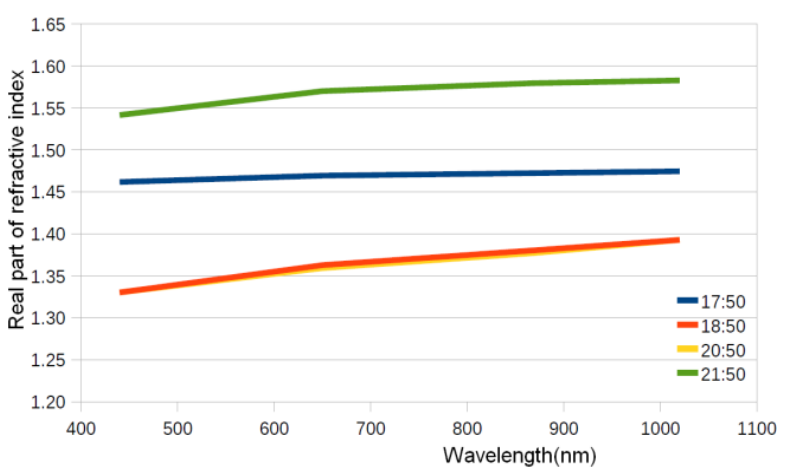

(a) Real part of refractive index (30 July 2006)

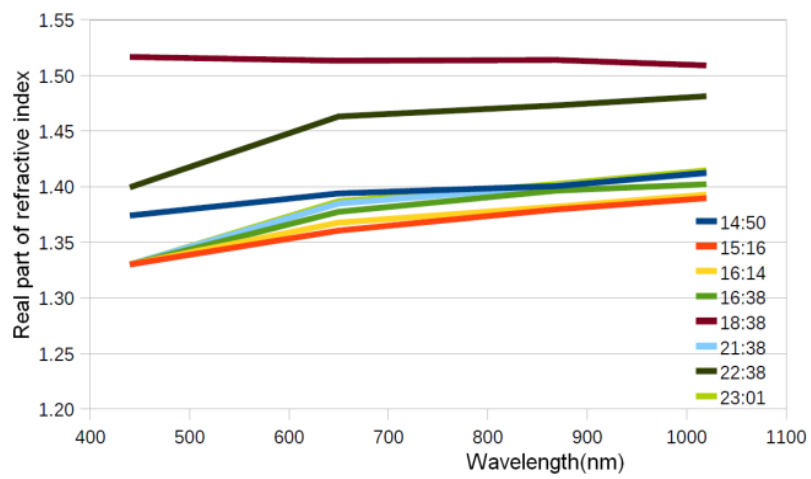

(b) Real part of refractive index (21 September 2008)

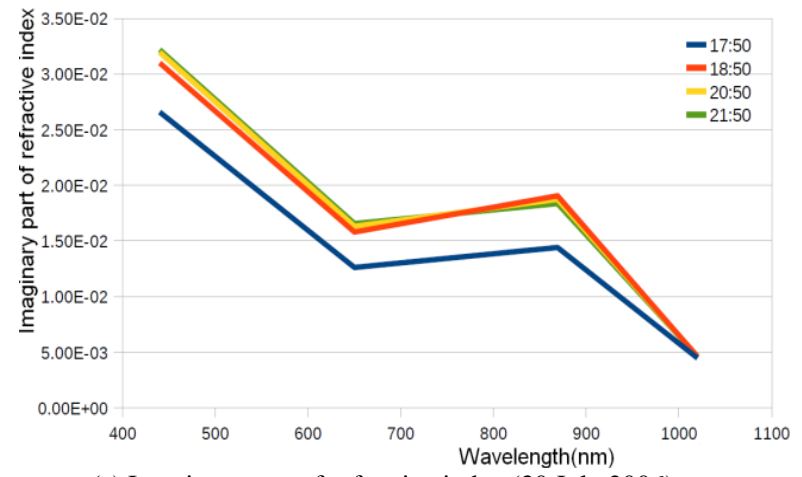

(c) Imaginary part of refractive index (30 July 2006) 


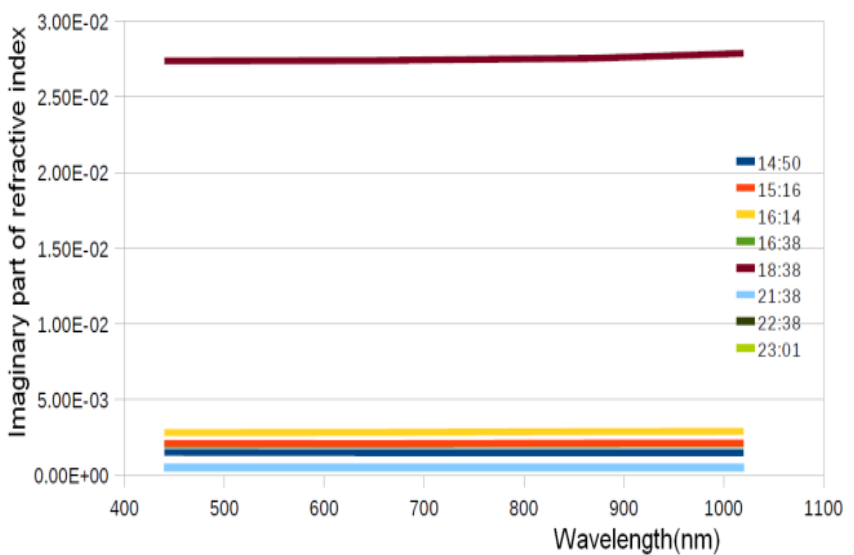

(d) Imaginary part of refractive index (21 September 2008)

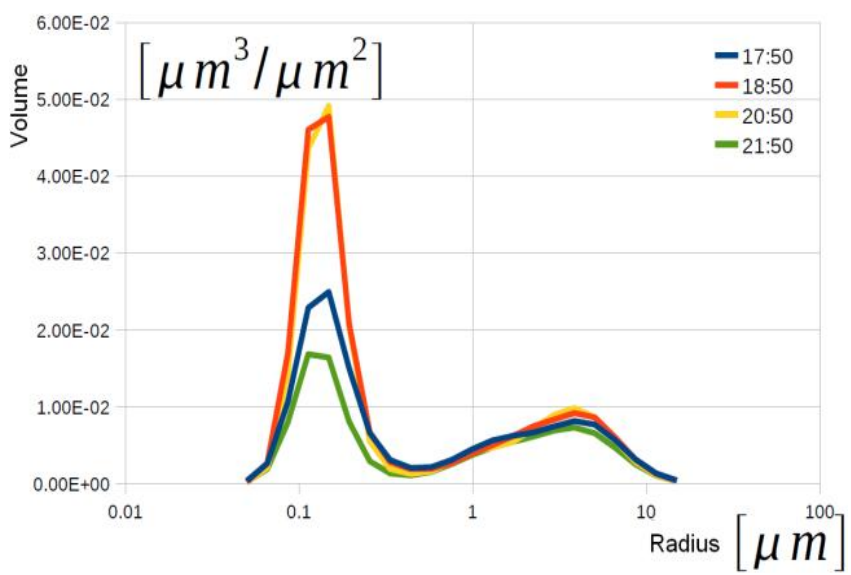

(e) Size distribution (Junge parameter $=3.108$, 30 July 2006)

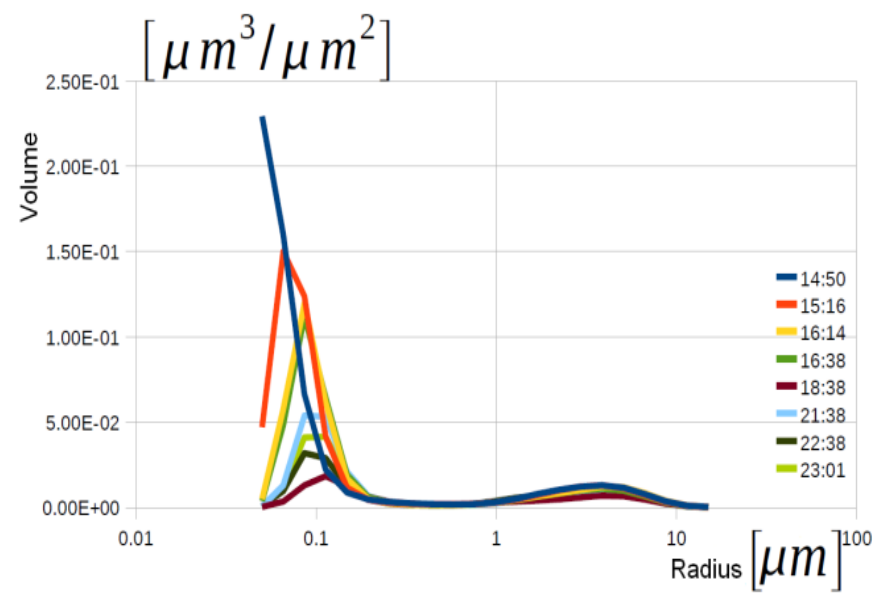

(f) Size distribution (Junge parameter=1.287, 21 September 2008)

Fig. 8. Estimated refractive index and size distribution with the measured skyradiometer data provided by Dr.K.Thome of NASA/ GSFC calculated based on the modified skyrad.pack ver.4.2.

Junge parameters calculated from Angstrom exponent of 2008 and 2006 are 3.108 and 1.287; the estimated complex refractive index was 1.51 -i0.028 and 1.35-i0.025. I show the estimation error of the thick atmosphere and optical scattering solar illumination (21) expressions that make up the complex refractive index real part and the imaginary part in Figure 9.

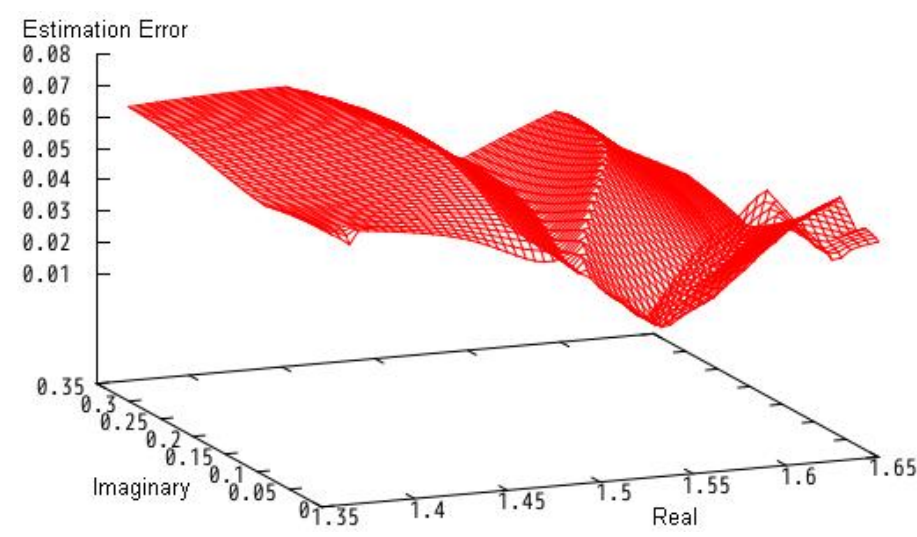

Fig. 9. An example of global minimum and local minima in estimation of refractive index which minimizes estimation errors of solar diffuse irradiance and atmospheric optical depth

There is a global optimal solution in the space of the solution, but the solution converges in local solution has a local solution of many other, and to satisfy the convergence condition (20) in the local solution, global you want to get truly optimal solution, that is, I would be complex refractive index is not found.

The optical thickness of the entire atmosphere in $500 \mathrm{~nm}$ of 2008 and 2006 are 0.186 and 0.261 . Complex refractive index of 2008 and 2006 is almost the same, but the 2006 has a small parameter Junge, who in 2008 is thin optical thickness. We also measured by $(20 \mathrm{~m}$ intervals $60 \mathrm{~m} \times 60 \mathrm{~m})$ ground surface of the test site is a Playa covered by a substantially uniform silica-based clay for several $10 \mathrm{~km}$ square or more, it was estimated ground reflectivity average . Using the EKO Instruments Co. MS720, measures the ground surface reflectance at $1 \mathrm{~nm}$ wavelength interval based on standard diffusion plate spectralon of LabSphere manufactured by (certified), and carried out the convolution integral of the spectral sensitivity characteristics of ASTER / VNIR I have to calculate the reflectance of each band of VNIR Te. These reflectance and solar zenith angle (18:32:05 UTM respectively, 18:33:34 UTM) in the satellite pass time of observation date, the sun azimuth angle, observation zenith angle, ground surface pressure (hPa), total ozone (DN), I is shown in Table 2 $(\mathrm{cm})$ the total amount of water vapor. Moreover, the volume particle size distribution that ground surface reflectance was measured, was determined from the sky radiometer data, the top of atmosphere radiance Last calculated from ASTER / VNIR data, to obtain the phase function with a complex refractive index, MODTRAN multiple scattering is calculated by, further, the top of atmosphere radiance Lave obtained by considering these computed by MODTRAN absorption total ozone by steam total, the number of data of the thickness atmospheric optical only complex refractive index and particle size distribution volume particle size distribution was estimated from Aureolemeter data and $\mathrm{L}_{\mathrm{jung}}$ to obtain the coefficients of the power distribution, was modified to use a complex refractive index empirical and compared with $\mathrm{L}_{\text {aero }}$ using a complex refractive index. I show the comparison results in Table 3. (7), the band according to its deviation a biased manner have been identified between the calibration factor according to an alternative calibration that is performed 
here with the calibration factor obtained by using the data of the on-board calibration system ASTER / VNIR is to be 10,5,3 percent in the order $1,2,3$ [30].

TABLE II. ATMOSPHERIC AND SURFACE CONDITIONS AT THE TEST Site Of RaIlRoAd VALley Playa On July 302006 AND SEPTEMBER 21 2008

\begin{tabular}{|c|c|c|c|c|}
\hline $\begin{array}{l}\text { Observatio } \\
\text { Date }\end{array}$ & $\begin{array}{l}\text { on Solar } \\
\text { Column } \\
\text { zenith } \\
\text { water }\end{array}$ & $\begin{array}{l}\text { lar } \\
\mathrm{R}_{\text {band1 }} \mathrm{R}_{\text {band2 }} \mathrm{R}_{\text {band3 }} \\
\text { azimuth pressure } \\
\text { 560nm 675nm 810nm }\end{array}$ & $\begin{array}{l}\text { Off-Nadir } \\
\text { angle }\end{array}$ & $\begin{array}{l}\text { Column } \\
\text { ozone }\end{array}$ \\
\hline $2006 / 7 / 30$ & $\begin{array}{l}25.37 \\
2.52\end{array}$ & $\begin{array}{ccc}136.1 & 857 \\
0.242 & 0.276 & 0.297\end{array}$ & 0 & 248.8 \\
\hline $2008 / 9 / 21$ & $\begin{array}{l}40.22 \\
0.82\end{array}$ & 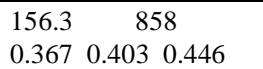 & 0 & 232.5 \\
\hline
\end{tabular}

TABLE III. COMPARISON AMONG ASTER DERIVED TOA RADIANCE (LAST), ESTIMATED TOA RADIANCE WITH THE AVERAGED VOLUME SPECTRA AND REFRACTIVE INDEX (LAVE), ESTIMATED TOA RADIANCE WITH POWER LAW SIZE DISTRIBUTION WITH EMPIRICAL REFRACTIVE INDEX (LJUNG) AND ESTIMATED TOA RADIANCE WITH AERONET DATA (LAERO)

\begin{tabular}{|l|l|l|l|l|l|l|l|l|}
\hline $\begin{array}{l}\text { Observation } \\
\text { Date }\end{array}$ & $\begin{array}{l}\text { ASTE } \\
\text { R } \\
\text { VNIR }\end{array}$ & Last & Ljung & $\begin{array}{l}\% \text { diff. } \\
\text { Ljung }\end{array}$ & Lave & $\begin{array}{l}\text { \%diff. } \\
\text { Lave }\end{array}$ & Laero & $\begin{array}{l}\text { \%diff. } \\
\text { Laero }\end{array}$ \\
\hline $\begin{array}{l}\text { July 30 } \\
2006\end{array}$ & Band1 & 137.74 & 122.40 & 12.529 & 124.50 & 10.631 & 122.76 & 12.197 \\
\cline { 2 - 9 } & Band2 & 116.07 & 113.89 & 1.912 & 115.39 & 0.592 & 114.64 & 1.245 \\
\cline { 2 - 9 } & Band3 & 89.43 & 83.48 & 7.130 & 82.79 & 8.026 & 83.89 & 6.602 \\
\hline \multirow{2}{*}{\begin{tabular}{l} 
September 2008 \\
\cline { 2 - 9 }
\end{tabular}} & Band1 & 168.96 & 153.66 & 9.958 & 153.00 & 10.431 & 154.26 & 9.526 \\
\cline { 2 - 9 } & Band2 & 140.63 & 141.85 & -0.860 & 140.98 & -0.251 & 142.54 & -1.344 \\
\cline { 2 - 9 } & Band3 & 105.65 & 109.60 & -3.601 & 107.30 & -1.540 & 110.04 & -3.991 \\
\hline
\end{tabular}

Deviation of the July 30, $2006 \mathrm{~L}_{\text {aero }}$ and $\mathrm{L}_{\mathrm{ave}}$ and $\mathrm{L}_{\mathrm{ast}}$ of Table 3 is almost the same, there is a gap of around 5\% deviation of September 21, 2008. In addition, I have shown that people of $\mathrm{L}_{\text {ave }}$ deviation and $\mathrm{L}_{\text {ast }}$ to close (7) to (18) between the bias of the alternative calibration factor with the on-board calibration factor over 10 years than the deviation from the $\mathrm{L}_{\mathrm{ae}}$ or

Asked the complex refractive index and volume particle size distribution (sun direct light, rim light, scattered light) from the sky radiometer data of September 21, 2008, (xxxVolume, $\mathrm{xxx}$ represents the wavelength $\mathrm{nm}$ here) top of atmosphere radiance estimated. Determined Junge parameters of the number power distribution from the spectral characteristics of the thick atmosphere optically. As a result, the atmosphere (xxxPlMea) when using a complex refractive index calculated on the (xxxPIEnp) when using the experience in the complex refractive index.

I compared to the top radiance. That is, a comparison for evaluating the error when estimating the upper atmospheric radiance using Junge parameters obtained relatively easily. At this time, the solar zenith angle and was assessed as a function of the observation zenith angle other times, as can also be applied to other sensors of this evaluation result. As shown in Figure 10, (0 degrees observation zenith angle), the difference of the top of atmosphere radiance and (1.44-i0.005 experience value) number of power distribution and volume particle size distribution of 0.1 if the nadir results. I found that also $2.3 \mathrm{~W} / \mathrm{m}^{2} / \mathrm{sr}$, from, the difference number of the power law distribution (measured value $1.51-\mathrm{i} 0.028$ ) is $1.3 \mathrm{~W} / \mathrm{m}^{2} / \mathrm{sr}$ from 0.8 .

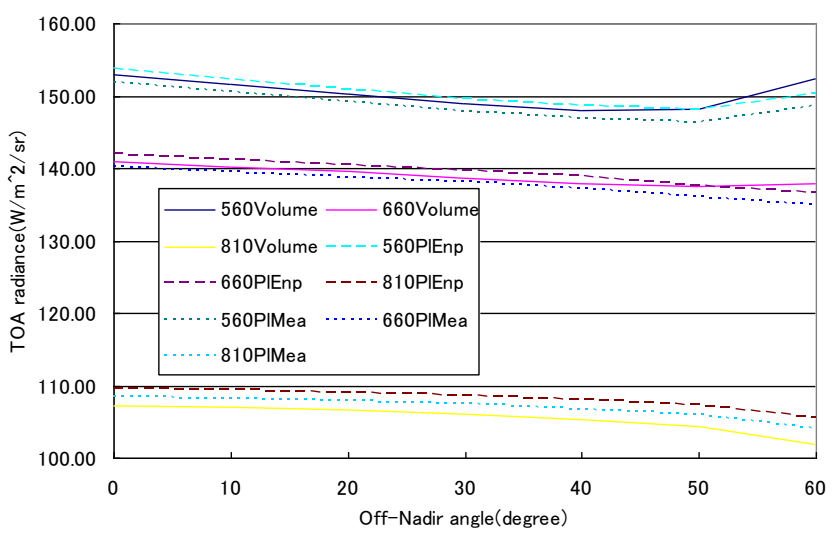

(a) Observation zenith angle dependency

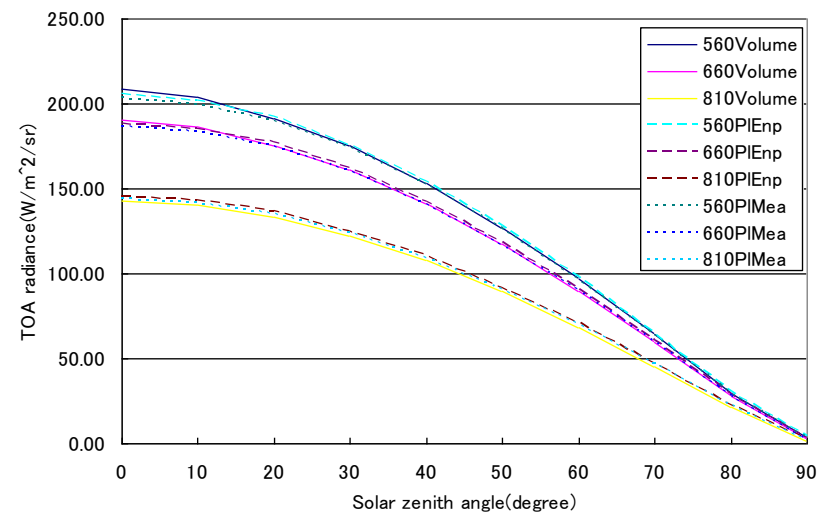

(b) Solar zenith angle dependency

Fig. 10. Difference of estimated top of the atmosphere radiance with volume spectra of size distribution and power law distributions and their off-nadir angle dependency as well as solar zenith angle dependency for the field campaign at Railroad Valley playa on September 21 2008. Where xxxVolume denotes TOA radiance calculated with volume spectra and measured refractive index at $\operatorname{xxx}(\mathrm{nm})$ of wavelength while $x x x P 1 E n p$ denotes that with power law of size distribution with the empirical refractive index(1.44-i0.005) and xxxPlMea denotes that with power law size distribution with the measured refractive index(1.51-i0.028).

In addition, I found that this difference is larger observation zenith angle increases. Think anyone who wants to estimate solar direct light, rim light, by scattering light measurement value the complex refractive index and volume particle size distribution is the best to the top of atmosphere radiance estimated that these measurements are not possible, atmospheric optical it was found that the difference is 1,2\% to estimate the parameters of the number of power distribution only from the measurement data of the thickness, even if the estimated top of atmosphere radiance using a complex refractive index empirical. It was also found that if it is possible to measure the complex refractive index difference between the two is less than $1 \%$. Therefore, estimation of the complex index of refraction in the case of using the Junge parameter is important, but the method for measuring the polarization component of the atmospheric scattering light using a portable handy polarized radiometer small and 
lightweight even for this is also proposed by the authors 30 you have). At this time, I is shown in Figure 11 the difference in phase function.

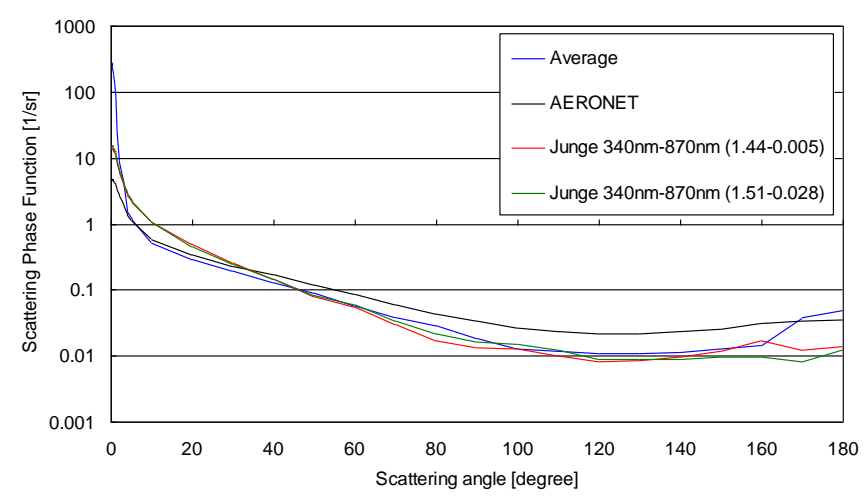

Fig. 11. Difference of phase function at $675 \mathrm{~nm}$ with volume spectra and power law based size distributions for the field campaign at Railroad Valley playa on September 21 2008. Average denotes the phase function with volume spectra derived from skyradiometer data while AERONET denotes that with size distribution derived from AERONET data. "Junge" denotes phase function with Junge parameters derived from optical depth at $340 \mathrm{~nm}$ and $870 \mathrm{~nm}$ and with $1.44-0.005 \mathrm{i}$ of empirical refractive index as well as with measured index of 1.51-0.028i.

Symbol Average in the figure is a phase function that was calculated using the complex refractive index and the volume particle size distribution was determined using a sky radiometer data, AERONET is a volume particle size distribution and the complex refractive index obtained from the AERONET data is a phase function determined by mie2new.f earlier using. Is a phase function that determines the Junge [29] Junge parameters from aerosol optical thickness of $870 \mathrm{~nm}$ and $340 \mathrm{~nm}$, was determined using the empirical values and measured values of the complex refractive index thereto. I found that towards the phase function of Junge is larger than the forward scattering AERONET, also, represents the backscattering is small, and the difference between the experiences with the actual value of the complex index of refraction is insignificant. Therefore, the person in the case of Junge, the greater the top of atmosphere radiance than AERONET. However, the difference between the top of atmosphere radiance is about $3 \%$, as described below.

Complex refractive index respectively and Figure 12, 13 shows the variation of the top of atmosphere radiance to changes in particle size distribution. Was calculated assuming the observed brightness of ASTER is the top of atmosphere radiance. I can be seen from these, the top of atmosphere brightness is less complex refractive index imaginary part is increased; the top of atmosphere brightness also increases Junge parameter increases. However, the tendency is small, it is $153 \pm 2\left[\mathrm{~W} / \mathrm{m}^{2} / \mathrm{sr} / \mu \mathrm{m}\right]$ the real part of the complex refractive index can be made to change $1.5 \pm 0.15$, i.e., an error of $10 \%$ even occurred I see that. In addition, the imaginary part is a $153 \pm 0.5\left[\mathrm{~W} / \mathrm{m}^{2} / \mathrm{sr} / \mu \mathrm{m}\right]$ also be $0.015 \pm 0.0015$ change, further, in the case of the Junge parameter is varied and $3 \pm 0.3$ $153 \pm 2\left[\mathrm{~W} / \mathrm{m}^{2} / \mathrm{sr} /\right.$ was found to vary with $\left.\mu \mathrm{m}\right]$. That is, it is understood that it is not only an error of $1.31 \%$ to the top of atmosphere radiance also expects $10 \% \pm$ the estimation error thereof.

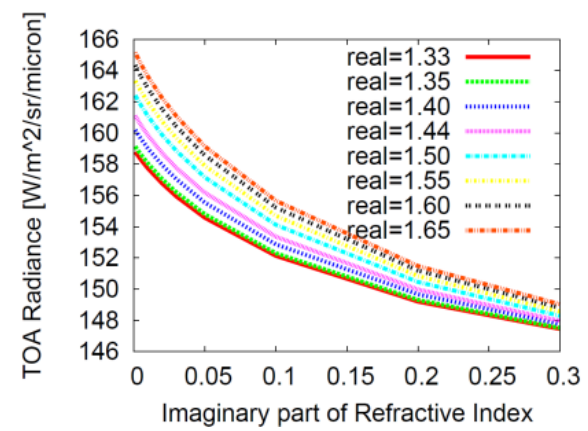

(a) Band $1(560 \mathrm{~nm})$

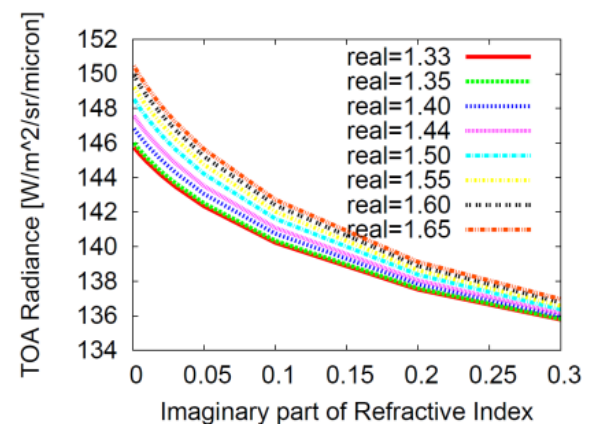

(b) Band 2(660nm)

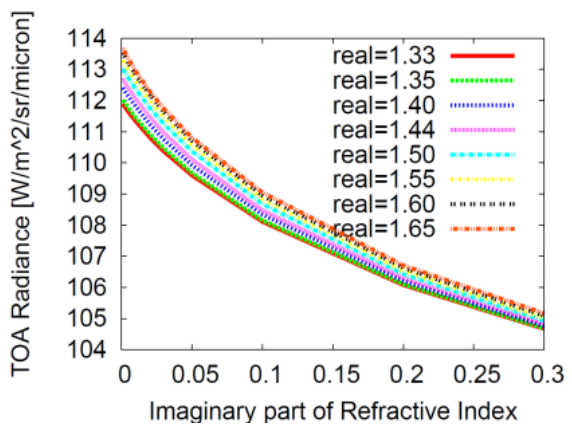

(c) Band 3N (810nm)

Fig. 12. Calculated TOA radiance derived from the field campaign at Railroad valley on September 212008 with the parameters of real and imaginary parts of refractive index.

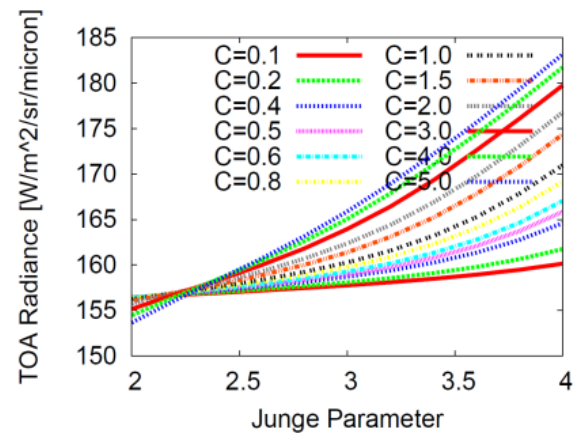

(a) Band 1(560nm) 


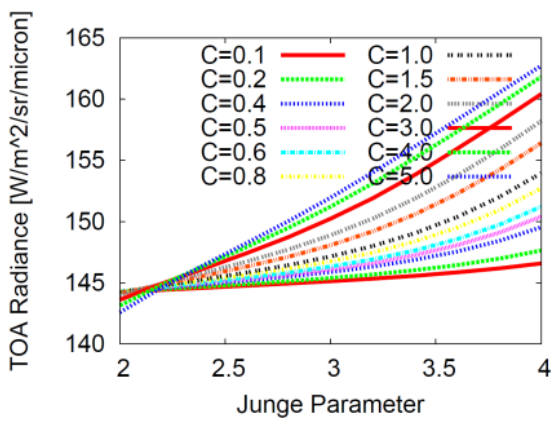

(b) Band 2(660nm)

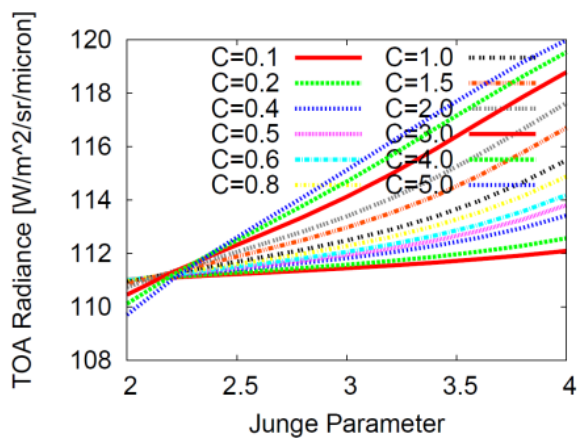

(c) Band 3N (810nm)

Fig. 13. Calculated TOA radiance as a function of Junge parameter derived from the field campaign at Railroad valley on September 212008 with the parameters of real and imaginary parts of refractive index where $n(r)=C 10^{v+1}$ $(r \leq 0.1 \mu m)$ and $n(r)=C r^{-(v+1)}(r>0.1 \mu m)$.

\section{CONCLUSION}

Complex refractive index empirical and complex index of refraction and (volume particle size distribution) particle size distribution based solar direct, peripheral light, the scattered light measurement and I used the number power law distribution, which is calculated from the spectral characteristics of the thick atmosphere optical result of comparing the top of atmosphere radiance case, it was found to be $1,2 \%$. Therefore, tolerances that must be assumed in the alternative calibration bringing the test site instruments heavy relatively large as Aureolemeter and sky radiometer is difficult revealed.

Further, the estimated scattering phase function complex refractive index to aerosol complex refractive index in the case Junge parameter, or if the thickness atmosphere optically thin small and errors of particle size distribution estimation has assumed measured scattering phase function and using a particle size distribution it was found that due to the convergence of iterative solution when to fit with.

Further, we estimate error analysis of the particle size distribution and aerosol complex refractive index, the estimation error of the top of atmosphere radiance, i.e., as in the alternative calibration error is about $1.3 \%$ Even $10 \%$ even if an error of these I made it clear to. Therefore, if such an alternative calibration test site thin thickness atmospheric optical particularly understood that a (solution does not converge if more) $2,3 \%$ request for calibration accuracy of the sky radiometer .

\section{ACKNOWLEDGMENT}

The author would like to thank Dr. Kenta Azuma for his efforts through experiments and simulations.

\section{REFERENCES}

[1] Arai K., Preliminary assessment of radiometric accuracy for MOS-1 sensors, International Journal of Remote Sensing, 9, 1, 5-12, 1988.

[2] Barker, JL, SK Dolan, et al., Landsat-7 mission and early results, SPIE, 3870, 299-311, 1999

[3] Barnes, RA, EEEplee, et al., Changes in the radiometric sensitivity of SeaWiFS determined from lunar and solar based measurements, Applied Optics, 38, 4649-4664, 1999.

[4] Gellman, DI, SF Biggar, et al., Review of SPOT-1 and 2 calibrations at White Sands from launch to the present, Proc. SPIE, Conf.No.1938, 118125, 1993.

[5] Folkman, MA, S.Sandor, et al., Updated results from performance characterization and calibration of the TRWIS III Hyperspectral Imager, Proc. SPIE, 3118-17, 142, 1997.

[6] Hagolle, O., P.Galoub, et al., Results of POLDER in-flight calibration, IEEE Trans. On Geoscience and Remote Sensing, 37, 1550-1566, 1999.

[7] Thome, K., K. Arai, S. Tsuchida and S. Biggar, Vicarious calibration of ASTER via the reflectance based approach, IEEE transaction of GeoScience and Remote Sensing, 46, 10, 3285-3295, 2008.

[8] Cosnefroy, H., M.Leroy and X.Briottet, Selection and characterization of Saharan and Arabian Desert sites for the calibration of optical satellite sensors, Remote Sensing of Environment, 58, 110-114, 1996.

[9] Arai, K., In-flight test site cross calibration between mission instruments onboard same platform, Advances in Space Research, 19, 9, 1317-1328, 1997.

[10] Nicodemus, FE, "Directional Reflectance and Emissivity of an Opaque Surface", Applied Optic (1965), or FE Nicodemus, JC Richmond, JJ Hsia, IW Ginsber, and T. Limperis, "Geometrical Considerations and Nomenclature for Reflectance, ", NBS Monograph 160, US Dept. of Commerce (1977).

[11] Slater, PN, SFBiggar, RGHolm, RDJackson, Y.Mao, MSMoran, JMPalmer and B.Yuan, Reflectance-and radiance-based methods for the in-flight absolute calibration of multispectral sensors, Remote Sensing of Environment, 22, 11-37, 1987.

[12] Kieffer, HH and RL Wildey, Establishing the moon as a spectral radiance standard, J., Atmosphere and Oceanic Technologies, 13, 360375, 1996.

[13] Arai, K., Atmospheric Correction and Residual Errors in Vicarious Cross-Calibration of AVNIR and OCTS Both Onboard ADEOS, Advances in Space Research, 25, 5, 1055-1058, 1999.

[14] Liu;. JI, Z. Li, YL Qiao, Y.-J. Liu, and Y.-X. Zhang, A new method for cross-calibration of two satellite sensors, Int J. of Remote Sensing, 25 , $235267-5281,2004$.

[15] Kohei Arai , error analysis of vicarious calibration of satellite visible and near infrared radiometer based KJThome, reflectance, Japan Photogrammetry Journal, Vol.39, No.2, pp.99-105, (2000 ) .

[16] Arai, K., Vicarious calibration for solar reflection channels of radiometers onboard satellites with deserted area of data, Advances in Space Research, 39, 1, 13-19, 2006.

[17] Arai, K. and X.Liang, Characterization of aerosols in Saga city areas, Japan withy direct and diffuse solar irradiance and aureole observations, Advances in Space Research, 39, 1, 23-27, 2006.

[18] Kohei Arai, vicarious calibration of ASTER / VNIR based on long-term observations of the optical properties of aerosols in Saga, Journal of the Remote Sensing Society of Japan , 28,3,246 over 255,2008

[19] Kohei Arai , applied linear algebra, modern science, Inc. , 2006

[20] Nakajima, T., M.Tanaka and T. Yamauchi, Retrieval of the optical properties of aerosols from aureole and extinction data, Applied Optics, 22, 19, 2951-2959, 1983.

[21] Kohei Arai , complex refractive index of aerosol using direct sun beams Xing Ming, by simulated annealing, and a peripheral light scattering and simultaneous estimation of particle size distribution, Journal of the Remote Sensing Society of Japan, Vol.23, No.1, pp .11-20,2003. 
[22] Arai K. and X.Liang, Method for the top of the atmosphere radiance estimation taking into account the polarization in down and up welling radiance calculations, Journal of the Japanese Society for Photogrammetry and Remote Sensing, 44, 3, 4 - 12 , 2005. Sun direct -based

[23] Kohei Arai , Liang Xing Ming, to improve Langley method and improve the calibration accuracy of the ambient light meter , ,47,4,21 28, 2008 Japan Society of Photogrammetry

[24] Teruyuki Nakajima, Glauco Tonna, Ruizhong Rao, Paolo Boi, Yoram Kaufman, and Brent Holben, Use of sky brightness measurements from ground for remote sensing of particulate polydispersions, "Appl. Opt. 35, 2672-2686, 1996.

[25] Box and Deepak, An Approximation to Multiple Scattering in the Earth's Atmosphere: Almucatar Radiance Formulation, Journal of the Atmospheric Sciences, 38, 1037-1048, 1981.

[26] Kohei Arai , self-study remote sensing , Morikita publication , 2004

[27] Kohei Arai , Basic theory of remote sensing, academic book publishing , 2001 .

[28] Aoki, K., T. Takamura, and T. Nakajima, Aerosol optical properties measured by SKYNET skyradiometer validation network. Proc. Of the 2nd EarthCARE Workshop, 133-134, 2005.
[29] Lenoble, J. edt, Radiative transfer in scattering and absorbing atmospheres: Standard computational procedures, A.Deepak Publishing, 1985.

[30] Kohei Arai, Aerosol refractive index estimation with ground based polarization measurement data, Abstract of the 50th COSPAR (Committee on Space Research / ICSU) Congress, A3.1-0092-08 1, 985, Montreal, Canada, July, 2008

\section{AUTHORS PROFILE}

Kohei Arai, He received BS, MS and PhD degrees in 1972, 1974 and 1982, respectively. He was with The Institute for Industrial Science and Technology of the University of Tokyo from April 1974 to December 1978 also was with National Space Development Agency of Japan from January, 1979 to March, 1990. During from 1985 to 1987, he was with Canada Centre for Remote Sensing as a Post Doctoral Fellow of National Science and Engineering Research Council of Canada. He moved to Saga University as a Professor in Department of Information Science on April 1990. He was a councilor for the Aeronautics and Space related to the Technology Committee of the Ministry of Science and Technology during from 1998 to 2000 . He was a councilor of Saga University for 2002 and 2003. He also was an executive councilor for the Remote Sensing Society of Japan for 2003 to 2005 . He is an Adjunct Professor of University of Arizona, USA since 1998. He also is Vice Chairman of the Commission "A" of ICSU/COSPAR since 2008. He wrote 30 books and published 492 journal papers 